\title{
Achieving the New Curriculum for Wales
}

Wales has been on a reform journey since 2014, shaping and refining its strategies to improve education. Central to the Welsh journey for educational improvement is the quality of student learning, of the organisation of education, and of the curriculum. Following the development of a new curriculum framework and its planned roll out between September 2020 and 2022, the initial implementation strategy can be updated so the Curriculum for Wales moves from policy to action and is fully realised to contribute to learners' progression in all schools across the country.

This OECD Education Policy Perspectives summarises the findings from the report Achieving the New Curriculum for Wales (OECD, 2020 [1] $)$ and suggests actions for the next steps of a coherent implementation of the new curriculum to reach schools. Targeted actions propose to develop a shared understanding of what the vision looks like in practice in schools, to continue investing in Wales' commitment to co-construction and to consolidate policy coherence around schools. These actions aim to empower schools, middle tier education authorities and Government in Wales, with next steps suggested by the OECD for stakeholders to be able to implement the new curriculum. The full report provides the analysis and references that support this document.

\section{Achieving the Curriculum for Wales: introduction and methodology}

A thriving education system allows every student the opportunity to develop as an individual and strengthens a society's capacity for economic growth and well-being. Wales (United Kingdom) has been on a reform journey towards school improvement, focused on developing an education system led by commonly defined, learner centred purposes. In 2017, Wales outlined its reform agenda in Education in Wales: Our national mission, which encompasses five policy areas: curriculum; assessment and evaluation; equity, excellence and well-being; teaching; and leadership.

Following expert assessments, consultations with the education profession, and national discussions about education, curriculum change became the spearhead of this reform journey. Each of the other policy areas - "enabling objectives", as referred to in Wales - aim to contribute to turn the new curriculum into reality. To progress, the Welsh Government has developed the new national curriculum framework and assessment arrangements in collaboration with the education community. The draft framework was offered for public consultation between April and July 2019, to then be refined and tested by schools. Finalised versions of the curriculum and assessment arrangements were published in January 2020.

As part of its Implementing Education Policies programme, the OECD was invited and engaged with Wales to analyse its curriculum reform in the wider context of the country's education reform journey, and provide guidance on how the new Curriculum for Wales can be implemented effectively. Box 1 summarises the tailored methodology set in motion to this effect. 


\section{Box 1. Implementing Education Policies: a tailored methodology for Wales}

A specific OECD team bringing together OECD analysts and an external expert on curriculum design and implementation was brought together for this project. The team followed the project's methodology for implementation support, combining research with fieldwork, and engaging with stakeholders across Wales to ensure validity of the analysis and ownership of the recommendations. The team:

- documented key aspects of education policy in Wales; drew on qualitative and quantitative comparative data from benchmarking education performers and data provided by the Welsh Government and other institutions

- undertook two assessment visits to Wales in September and October 2019

- conducted additional phone interviews with stakeholders

- maintained regular exchanges with the national co-ordination team within the Welsh Government.

The project also built on the knowledge accumulated over six years of work between the OECD's Directorate for Education and Skills and Wales (OECD, 2018[3]; OECD, 2017[4]]; OECD, 2014[5]).

The OECD team's analysis and suggestions aim to help Wales tackle the main issues linked to the implementation of the new curriculum so schools and their students can reap the benefits from this ambitious change. It builds on the framework developed by Viennet and Pont $\left(2017_{[2]}\right)$ to explore the different elements that can contribute towards the effective implementation of the new Curriculum for Wales. The framework proposes a rational lens to those involved in policy making to analyse and plan action to enhance the effectiveness of education policy change processes. The framework suggests that to succeed in educational change, policy makers need to shape coherent implementation strategies that consider policy design, engage with stakeholders early on in the process, and take into account the policy context (Figure 1).

In Wales, in order to turn this curriculum change into reality, the Government and all stakeholders involved must maintain a coherent strategy as they progressively implement the new curriculum. In complex education systems, "implementation" is not about executing the policy, but more about building and fine-tuning it collaboratively. Consequently, it is important to understand how the design of the curriculum, the engagement of stakeholders and the context interact, and what they imply for the implementation process. 


\section{Figure 1. The Implementing Education Policies framework}

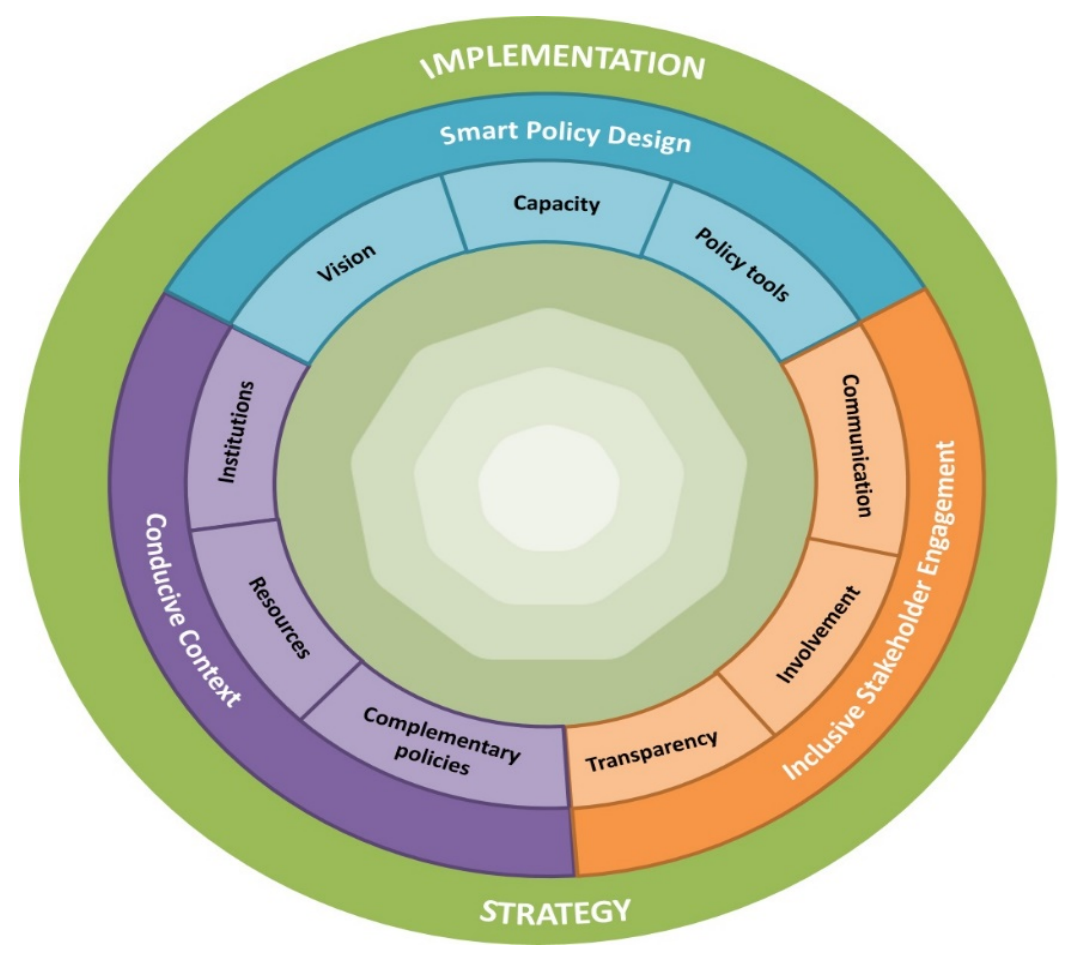

Source: adapted from Viennet and Pont (2017[2]), "Education policy implementation: a literature review and proposed framework", OECD Education Working Papers, No. 162, OECD Publishing, Paris, http://dx.doi.org/10.1787/19939019.

\section{Why transform the curriculum?}

Following a nationwide consultation in 2014 about what Wales wanted for its education system in the future, Welsh education stakeholders agreed upon the need for curriculum change, to a degree that held promise for actual change to take place. The Welsh Government acknowledged the result of the consultation and moved to make curriculum reform a central piece of its reform agenda detailed in Education in Wales: Our national mission. Wales' "national mission" consists of three objectives: raise school standards, reduce the attainment gap between different groups of learners, and ensure an education that is a source of national pride and public confidence (Welsh Government, 2017[6]).

The design of a policy plays a central role in its implementation, as the nature of a policy solution and the way it is formulated, influence how the policy plays out in reality. In particular, the vision and its justification, the type of policy tools and the capacity of those who have to implement it, can enable or interfere with the reform process. The literature on policy implementation further shows that an education policy is more likely to become reality if a strong case underpins the need for change (Viennet and Pont, 2017[2] $)$.

Wales has several reasons to transform its curriculum. First, the current curriculum does not seem adapted to guarantee the quality of learning experiences for all students in the future. Performance on international assessments such as PISA (Figure 2), national assessments and Welsh school inspectorate reports, found a continuous decline of student performance until 2015 which confirmed concerns about the quality of student learning (OECD, 2014 $\left.{ }_{[5]}\right)$. Reports also highlight the large variability of students' performance within Welsh schools in spite of a policy commitment to equity. A series of studies by international and Welsh experts and a large-scale consultation in Wales concluded that the national curriculum and assessment arrangements require significant changes to help Welsh learners thrive. A key component of the learning environment, curriculum is a policy lever used to support improvement in schools and in student learning (OECD, 2020[1]). 
Figure 2. Student reading performance and equity in education in Wales, PISA 2018

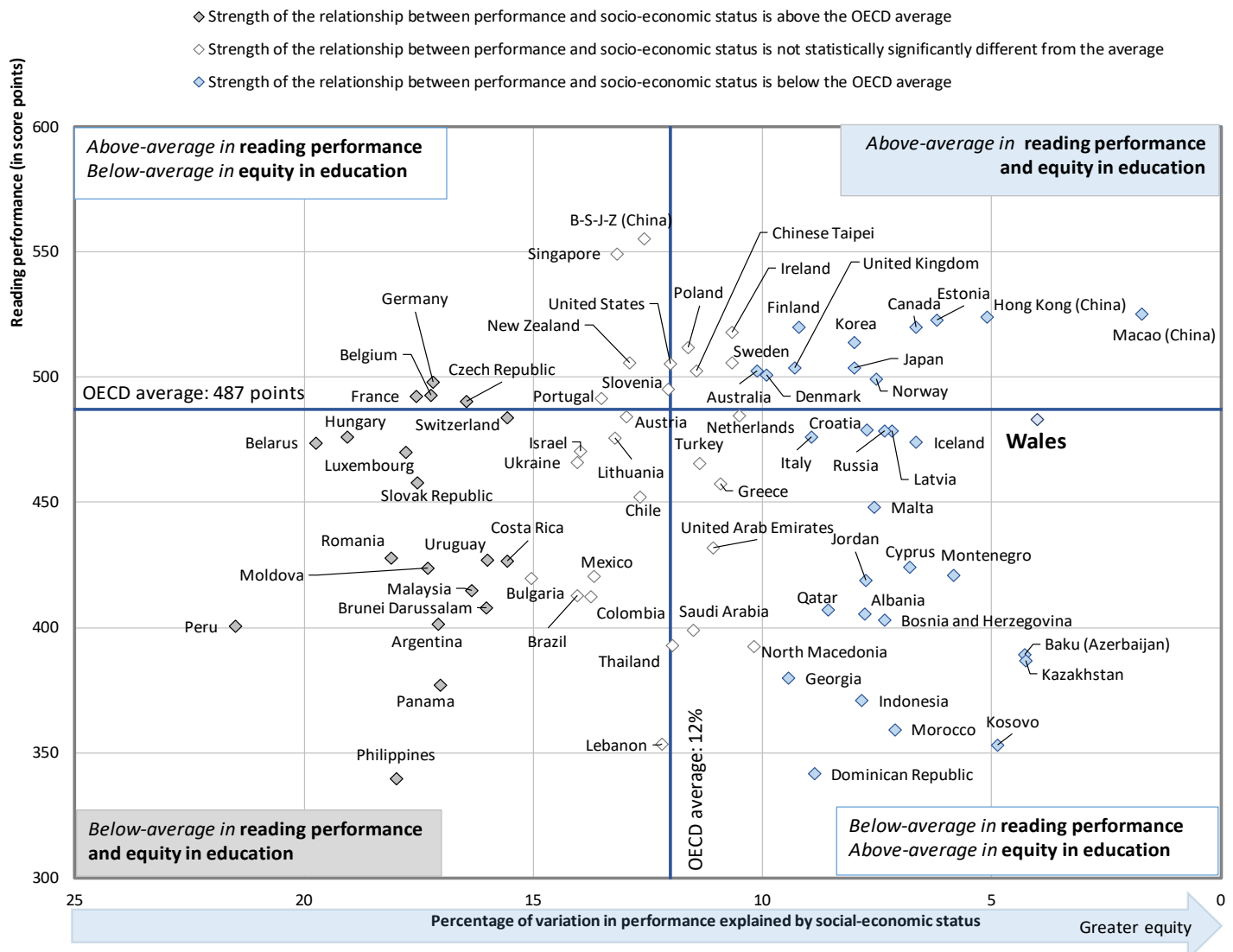

Note: Equity is measured by the strength of the relationship between performance and socio-economic status. Socio-economic status is measured by the PISA index of economic, social and cultural status. Information on statistical data for Israel: http://dx.doi.org/10.1787/888932315602.

Source: OECD (2020[1]) Achieving the New Curriculum for Wales, https://doi.org/10.1787/4b483953-en.

StatLink त्ञाजा https://dx.doi.org/10.1787/888934084361

\section{The Curriculum for Wales: overview}

The new Curriculum for Wales is aimed at all maintained (public) and funded schools for children aged 5 to 16 . It intends to provide all children equal access to a broad and balanced education of high quality, including students with additional learning needs. The new curriculum is built around the "four purposes" of education, a vision that guides the reform agenda so education enables Wales' youth to be:

- ambitious, capable learners, ready to learn through their lives

- enterprising, creative contributors, ready to play a full part in life and work

- ethical, informed citizens of Wales and the world

- healthy, confident individuals, ready to lead fulfilling lives as valued members of society.

The type of learning promoted is holistic, interdisciplinary, and integrates knowledge, skills and experience together. Learning is structured around six Areas of Learning and Experience (Figure 3) that pool individual subject disciplines, which schools are encouraged to link in a stronger and more meaningful way than in the past. The "statements of what matters" specify what is important to learn in each Area. The framework further builds around three cross-area competencies (literacy, numeracy and digital competency), and four "integral" competencies (creativity and innovation, critical thinking and problem-solving, personal 
effectiveness, and planning and organising). The Curriculum for Wales also revisits the role of assessment in students' learning progression and aims to move away from the formative versus summative dichotomy in student assessment. Assessment is promoted as a tool to support the progress of each individual learner in relation to the student-learning continuum from age 5 to 16 .

Figure 3. Six Areas of Learning and Experience of the Curriculum for Wales

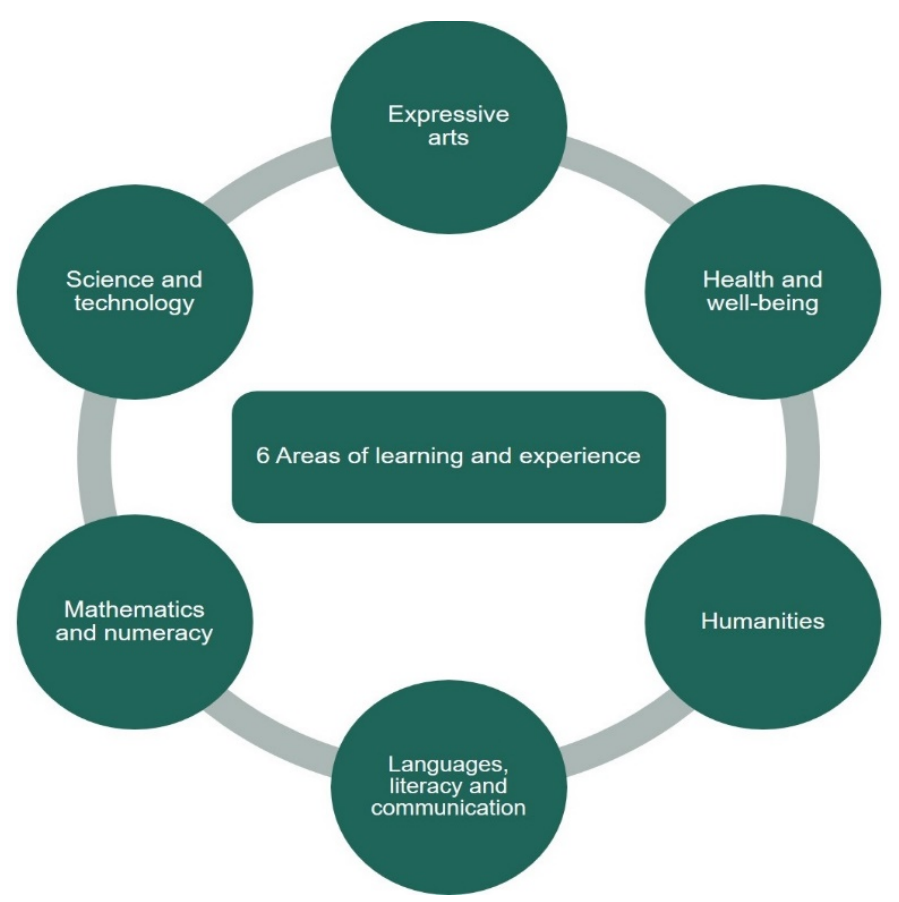

Source: OECD (2020[1]) Achieving the New Curriculum for Wales, https://doi.org/10.1787/4b483953-en.

Local design is a driving element of the new curriculum at the school level: a framework is established at the national level, but fully implementing the curriculum and assessment arrangements requires school-level design. The new curriculum framework aims to guide school communities in the elaboration of their own school curriculum instead of a national one that prescribes every aspect of learning. This approach aims to allow the curriculum to be more relevant to the local context and thus more engaging for students.

The Curriculum for Wales was developed over the course of several years and the final version of its framework documents was published in January 2020 (Welsh Government, 2020[7]). The four complementary policies (or "enabling objectives") of assessment and evaluation, teaching, leadership, and equity, excellence and well-being were also developed to help realise the new curriculum in schools. The curriculum designers included a large variety of stakeholders. Experts and government officials worked directly with a network of Pioneer schools and educators to design, test and refine the new curriculum before presenting the framework to the public for feedback and further refinement. The analysis in the present document is based on the version published for consultation in April 2019.

\section{Ready for curriculum implementation?}

The Welsh Government invited the OECD, through its Implementing Education Policies support programme, to provide an assessment of the implementation of the new Curriculum for Wales and to suggest the next steps. The Implementing Education Policies team analysed the new curriculum and its implementation through its analytical framework (Figure 1) by: 
- studying the design of the Curriculum for Wales, including its draft framework, student assessment arrangements, and its implications for schools' capacity, for equity and resources.

- observing how stakeholders co-constructed the new curriculum and the importance of their engagement for the success of the policy.

- reviewing the main contextual elements that could facilitate or hinder curriculum implementation, including the coherence between the current structure of school improvement, other central education policies, and the new curriculum.

- reviewing the strategy that allows for planning and leading the implementation process: Wales followed the Education in Wales: Our National Mission action plan to guide curriculum development from 2017 to 2021.

The OECD team considers that the implementation strategy should be adjusted to ensure the new curriculum is effectively implemented across Wales. Following an overview of progress and challenges ahead, this document presents four recommendations to help Wales in the next steps ahead for effective implementation.

\section{Progress made in shaping the future-oriented Curriculum for Wales}

Wales has a clear vision for its education system and for its learners, which inspires the new curriculum policy through the four purposes. The vision is future-oriented and resonates with those of many countries and education systems across the OECD. The vision and four purposes have become a shared language across Wales and drivers of action in policy and school practices. The degree to which stakeholders contributed to shape it and are now committed to the four purposes is a considerable strength to realise the curriculum successfully. The curriculum framework documents and the communication around the new policy show significant efforts to define clear objectives to serve the vision, thus facilitating action.

Wales has committed to shaping the Curriculum for Wales with multiple stakeholders through co-construction, which has required a high level of investment and has resulted in important progress in trust and in readiness for change. The curriculum framework and proposals for student assessment were co-developed and have gone through a feedback process for further refinement. There is recognition of the need to further develop the national guidance on student assessment and the educative materials to facilitate curriculum design at school level.

The Curriculum for Wales is being shaped alongside an international trend to develop curriculum frameworks building around big ideas and based on broad competencies, as opposed to curricula based solely on content knowledge or on skills. The new curriculum represents a significant shift from the national curriculum, with the aim to better respond to the context of the 21st century. These changes also include a new paradigm for learning progression, moving towards a continuum rather than a succession of stages of learning. Assessment approaches that align to the new curriculum are being piloted, such as adaptive online personalised assessments.

While they cannot be attributed directly to the latest reforms, recent progress in educational outcomes of 15-year-old students in PISA (Figure 4) might be linked to the ongoing change in culture and intense commitment to educational improvement in Wales. Maintaining this widespread positive attitude towards educational change is central as Wales prepares for the next step of curriculum implementation. 
Figure 4. Reading performance of 15-year-olds, Wales and OECD, PISA 2006-2018

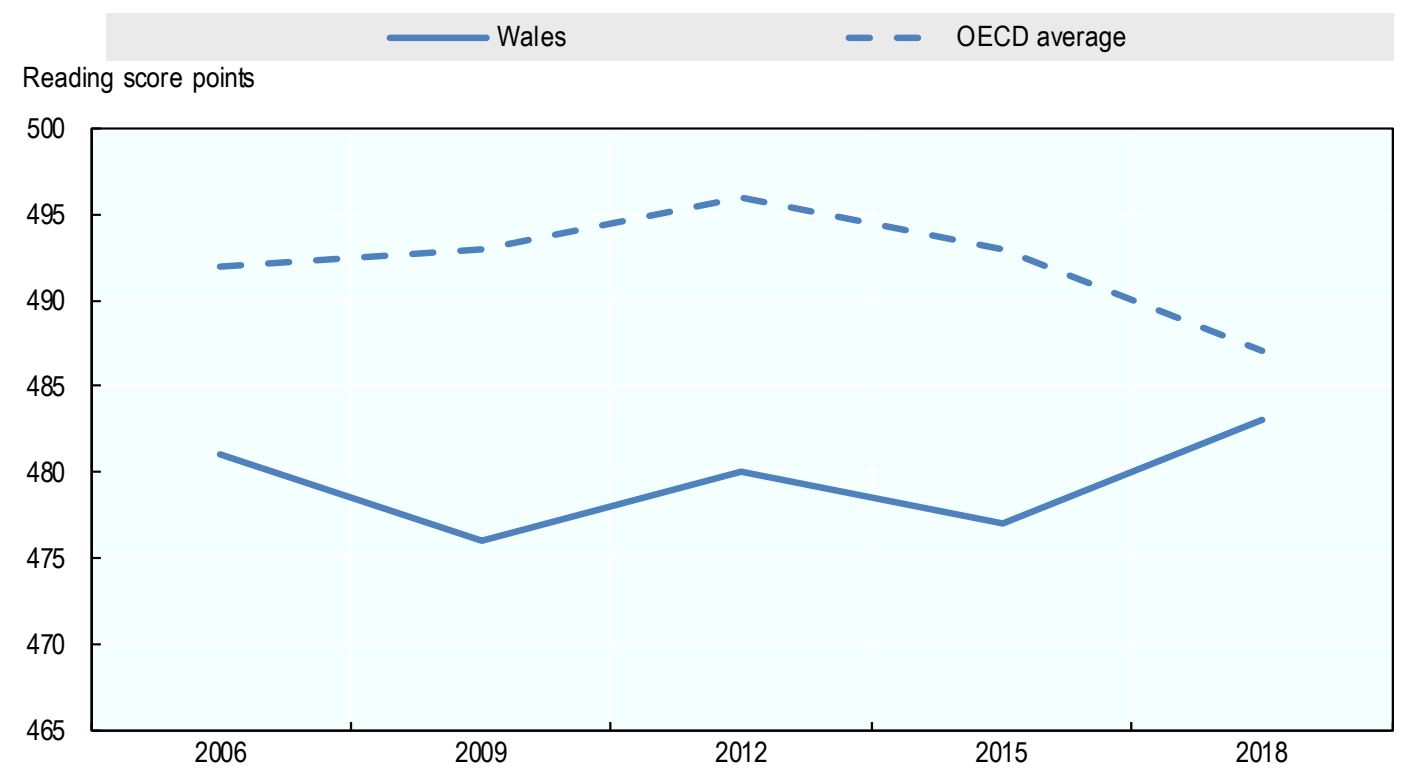

Note: In 2015 changes were made to the test design, administration, and scaling of PISA. These changes add statistical uncertainty to trend comparisons that should be taken into account when comparing 2015 results to those from prior years. Source: OECD (2020[1]) Achieving the New Curriculum for Wales, https://doi.org/10.1787/4b483953-en.

StatLink : ताI

\section{Co-construction has succeeded in engaging many and developing trust}

Wales should be acknowledged for its efforts to embed co-construction across the system as a principle for curriculum development and education policy making more generally. The Welsh Government has succeeded in getting a critical mass of stakeholders to support and commit to the changes, and informing curriculum development with practitioners' contributions as well as academic and policy experts. Many education professionals have been engaged across the board in working together to shape the future education system in Wales: teachers, experts, parents, students, school leaders, as well as those working across the middle tier. The Inspectorate for Education and Training (Estyn) and regional consortia have invested time throughout the whole process, to reconfigure school improvement and evaluation approaches that align to the needs of the new curriculum.

The co-construction process, led and managed by the Welsh Government, has built on three key mechanisms: the Pioneer School Network, a network of schools that was invited to initially lead on the design and development of the new curriculum for Wales, working groups and consultations (Figure 5). This process has given shape to different components around the Curriculum for Wales, including the curriculum framework, and has allowed for piloting different approaches to assessment. It has been effective in creating an environment of trust and collaboration that promotes engagement. Wales has also invested in having a clear communication strategy that has brought coherence to the different policy components and clarity on the vision, establishing a strong basis for education professionals to make the "national mission" their own.

Educators are convinced, in majority, that the new curriculum will make a positive difference for their students. The reform counts strong champions among stakeholder groups such as teachers, head teachers and middle-tier organisations. It would seem that the early champions who have been involved longer with the new curriculum are strong advocates for it. Beyond their commitment, many education professionals expressed they felt ready and supported to change to a new curriculum (OECD, 2020[1]). 
Figure 5. Co-construction dynamics of the Curriculum for Wales

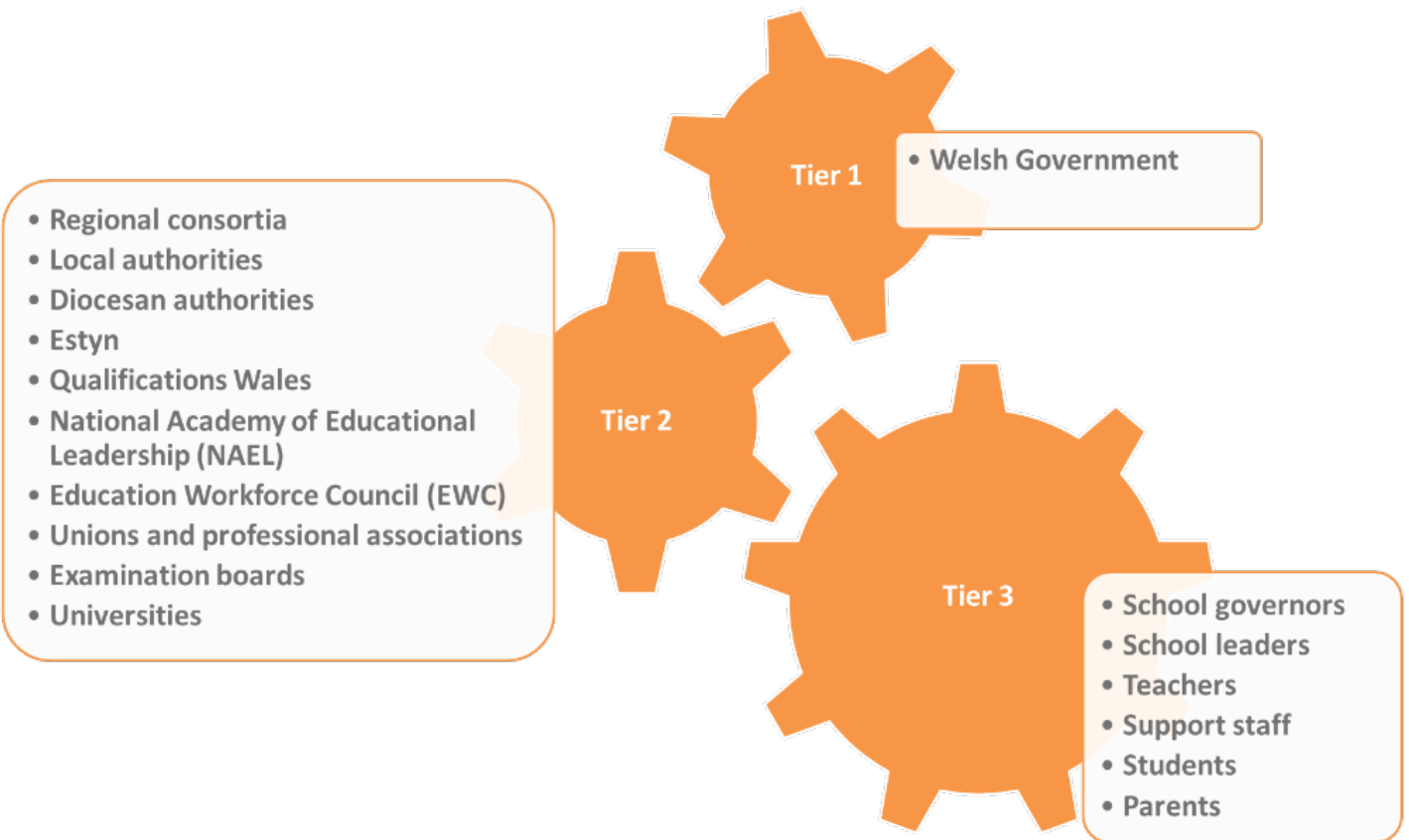

Source: OECD (2020[1]) Achieving the New Curriculum for Wales, https://doi.org/10.1787/4b483953-en.

\section{Contextual elements have helped set in motion a professionally-led education system}

The shift from what had become a managerial education system to one based on trust and professionalism builds on a favourable political and policy environment in Wales. Most parties and governance processes are aligning behind the curriculum, which is crucial to its successful implementation. The school improvement infrastructure is consolidated, with local authorities and regional consortia supporting schools. Regional consortia channel their efforts into making sure that all schools are equally involved with the new curriculum. There are examples of good collaboration between the consortia in several areas such as leadership development and the implementation of schools as learning organisations.

Many policies complementary to the Curriculum for Wales are also evolving in the same direction. Efforts were necessary to make the education reform journey a coherent one, given the large number of policies implied (Figure 6). Wales invested in the quality of education professionals with the development of professional standards for teachers and school leaders, the creation of a National Approach to Professional Learning, investments in initial teacher education, and the creation of a National Academy for Educational Leadership (NAEL). Assessment and evaluation approaches are in the process of shifting from a high-stakes environment to one based on professionalism and self-evaluation. Estyn, Qualifications Wales, regional consortia and the Welsh Government made efforts to develop new frameworks for qualifications and for accountability, including school self-evaluation resources, and to enhance system-level monitoring. 
Figure 6. Policy coherence for systemic educational success in Wales

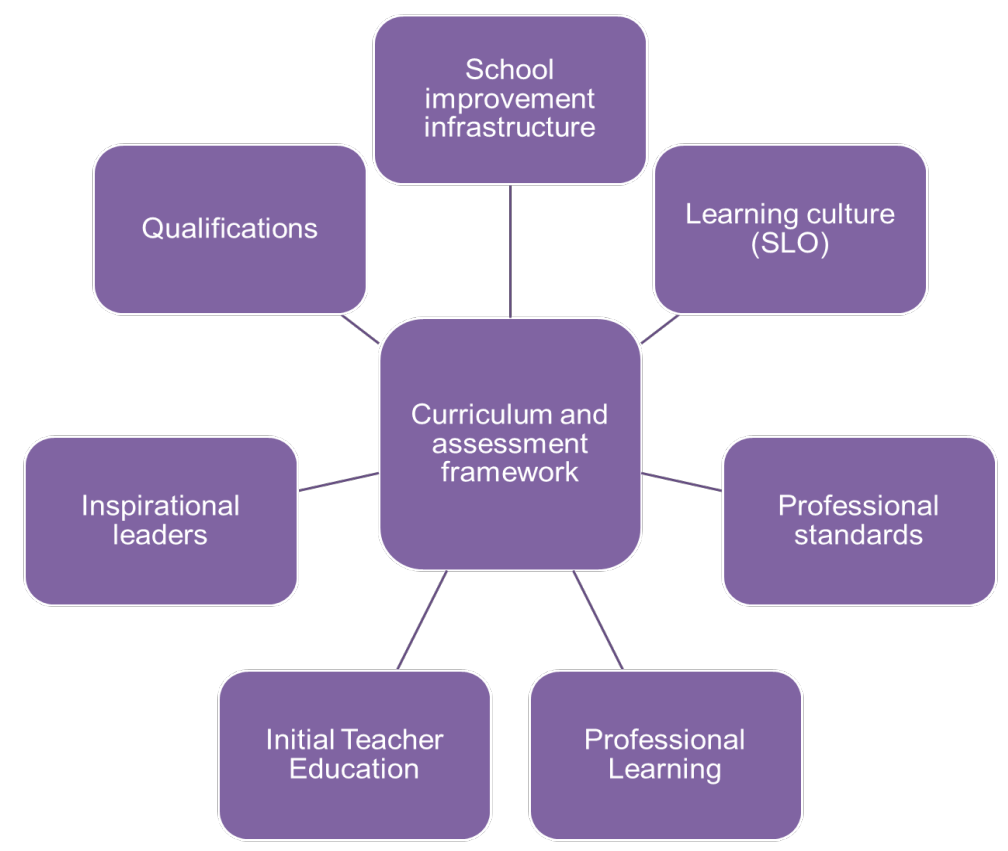

Source: OECD (2020 [1]) Achieving the New Curriculum for Wales, https://doi.org/10.1787/4b483953-en.

\section{The action plan 2017-2021 was conducted in a strategic and flexible manner}

An implementation strategy refers to the actions taken following a decision on the design of a policy for it to become a reality. The policy itself may be defined in a document that provides an overarching vision but the implementation strategy needs to be action-oriented, and requires being flexible enough to be updated and adapted according to progress made and issues that may arise. A coherent implementation strategy is central to provide the numerous stakeholders involved with clarity on their responsibilities within implementation, the policy objectives, the scope of action necessary to succeed, the timeline, and the precautions to monitor the policy with relevant data (Viennet and Pont, 2017[5]).

Wales is used to developing implementation plans in education. For the current agenda and the development of the new curriculum especially, the document Education in Wales: Our national mission described the policy and introduced a detailed implementation strategy in 2017, leading up to 2021 . The document presented the main objectives and policies to accomplish them, including the Curriculum for Wales together with the enabling objectives. It provides an overview of the reform journey, and spells out the ambitions and actions for 2021 for learners, for the teaching profession, for the school system, for the middle tier and for the Welsh Government. While referring to the different policies in place separately, it brings together the vision, actions and timelines to develop the curriculum, and the four enabling objectives, and gives all the references that had led to this action plan (Welsh Government, 2017[6]).

Communication and information around the action plan have been clear and continuous across the country, with strong leadership from the top and regular updates through different channels. The groups that bring together a range of education stakeholders, such as the Change Board and the Strategic Education Delivery Group, in collaboration with the Welsh Education Directorate, have guided the action plan. These different groups meet and follow up on progress regularly (OECD, 2020[1]). The action plan has been flexible to accommodate education stakeholders as well as their needs and challenges. As part of this, the Curriculum for Wales and other policies were delayed or sequenced to ensure they were attainable, and there were some efforts to prioritise policy areas. The Welsh Government was planning to review the action plan following the OECD team's preliminary findings. 
As progress was made and 2021 is drawing closer, it is time for the implementation strategy to be updated. The next section analyses and proposes actions for consideration to support curriculum implementation starting in 2020, building on the analysis undertaken of the dimensions that influence its effectiveness, including policy design, inclusive stakeholder engagement and a conducive context underpinning a coherent implementation strategy (Viennet and Pont, 2017 [5]). It highlights next steps for the curriculum to be fully realised in schools across Wales.

\section{Focusing the implementation strategy from a school's perspective}

Wales has made considerable progress on its education reform journey. The OECD team observed that Wales has to strike a balance between showing continuity on this reform journey and acknowledging that the next steps of implementation have to place schools and their communities at the centre. Any lack of coherence or consistency in messages and actions could result in derailing investments and efforts made up to now to get the system ready for this change. Wales will move forward in a concrete and coherent way if it can sequence the actions needed to build concrete pathways between its vision for education, the new curriculum framework and its enabling policies.

Striking this balance implies continuing to pursue the reform course detailed in Education in Wales: Our national mission with a new emphasis: adopting a school's perspective and giving schools capacity and even more room in the next steps. This will allow maintaining engagement, coherence and consistency of the main messages, while at the same time ensuring that the curriculum is effectively realised in schools.

Taking a school's perspective implies holding the Welsh vision and its four purposes of education steady, while making sure there is a shared understanding of what that vision looks like in practice. This means clarifying what the vision and objectives imply for student learning in schools, and revising the actions in the plan to focus on realisation of the curriculum in schools in 2020 and beyond. It shifts the focus to making schools the centre of every action by asking concrete questions such as:

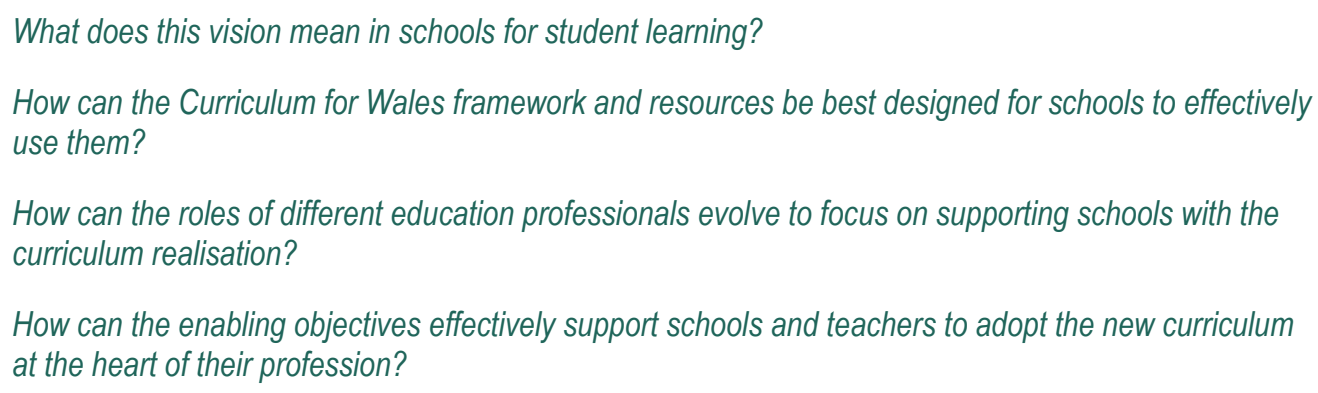

How can the enabling objectives effectively support schools and teachers to adopt the new curriculum at the heart of their profession?

At the time this document was finalised, the Welsh Government and the Strategic Education Delivery Group were discussing the next steps to facilitate implementation for schools and other practitioners. The OECD findings and the recommendations reproduced here served as input into these discussions. This proactive approach to policy making can make a difference in preparing for rollout with stakeholders.

The next steps of the implementation strategy should prioritise the actions based on what the system, and more specifically schools, need to roll out the new curriculum successfully starting from 2022 . The OECD team suggests that Wales adopt a school's perspective when considering its four recommendations to successfully implement the new curriculum and realise the four purposes of education (Figure 7). The next section develops each recommendation. 
Figure 7. Recommendations for next steps in the implementation of the Curriculum for Wales

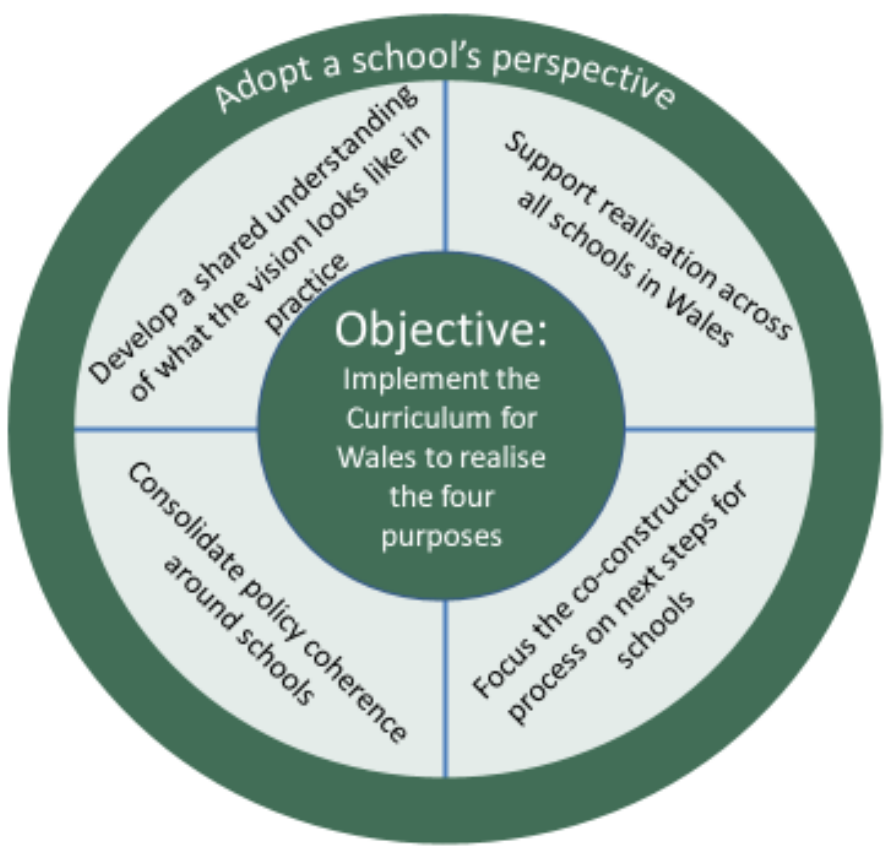

Source: OECD (2020[1]) Achieving the New Curriculum for Wales, https://doi.org/10.1787/4b483953-en.

\section{Recommendation 1: Developing a shared understanding of what the vision looks like in practice}

Realising the curriculum vision requires both commitment to it, and a shared understanding of what that vision looks like in practice, on the ground, in the day-to-day practice of teachers, leaders, teaching assistants and other school stakeholders, and in the experiences of children and young people. Stakeholders often make sense of the same policy messages in quite different ways, which can significantly affect implementation. The OECD team noted that this could be the case in Wales for some key elements of the new curriculum, including the practical and pedagogical implications of the four purposes.

At this stage of the curriculum journey in Wales, it is timely to focus on creating a shared vision of what successful realisation looks like in schools, for instance by asking questions such as:

What would we see in schools, classrooms and other learning settings that might suggest learners are experiencing opportunities to be ambitious, capable learners; enterprising, creative contributors; ethical informed citizens; and healthy, confident individuals?

What would "a professionally-led system" look like in schools in the course of their teaching days, weeks and years?

Responses to questions such as these appeared highly variable during the OECD team's visits, suggesting marked differences in how people make sense of new curriculum elements, and in particular what they consider to be practices reflective of the aspirations of the new curriculum. Reflecting collectively and finding common, concrete responses to these questions across the three tiers of Welsh education should be Wales' priority in the first six months of 2020.

The OECD team recommendation is to develop a shared understanding of what the vision looks like in practice. This should help initiate better coherence both internal within the curriculum, and external, with 
the enabling policies. Shared meaning will inform initiatives to develop capabilities across the system; clarify which resources are needed where; and help define relevant indicators and targets to monitor reform progress.

\section{Actions to consider}

Action 1.1: Develop a shared overarching vision of what the curriculum implies for practice in schools.

- This can be accomplished through collaboration between the Welsh Government (Education Directorate), schools, practitioners (including inspectors, etc.), representatives on the Strategic Education Delivery Group.

Action 1.2: Define associated operational objectives and indicators to monitor progress towards achieving the vision, including the implementation of the curriculum.

- The Welsh Government (Education Directorate) and the Strategic Education Delivery Group can define these objectives and monitor them in coherence with each other, and consider indicators available.

\section{Recommendation 2: Supporting the realisation of the curriculum across all schools in Wales}

A key challenge for the systems who, similarly to Wales, develop curriculum frameworks around big ideas and broad competencies is that big ideas must be clear enough to capture all the key concepts and knowledge learners are expected to learn about, while not being too prescriptive. The new curriculum marks a significant shift for primary and especially secondary education, potentially affecting work organisation for school leaders and teaching staff, timetables and transitions across levels of education. In parallel, a new approach to learning progression and student assessment is proposed, which requires schools to take ownership of the new approach and to design new forms of assessments. Developing quality content for learning and assessment and giving sufficient guidance for practitioners without being too prescriptive will be at the heart of successful implementation of the Curriculum for Wales.

The reform gives schools and teachers the role of curriculum designers with the responsibility to develop their own approach in support of the four purposes. Research shows that curriculum models that are less prescriptive and give more decision-making freedom to schools tend to be sustainable in the long term, but international experience shows that implementing school-level and local curriculum design in a system is challenging (OECD, 2020[1]). The Welsh Government and regional consortia have a role to play in providing high-quality professional learning, as well as educative curriculum material and guidance in support for teachers, while keeping true to the principle of local design. Moving forward, it will be crucial to take into account that the new curriculum demands new knowledge, skills and capabilities to be understood, designed and put into practice.

A key factor for the success of the new curriculum at the school level is the capacity of teachers, schools and their leaders, and the way the Welsh Government and middle-tier organisations can support them in continuously improving this capacity. Research suggests a number of competencies and practices such as collaboration for school leaders and teaching staff to master the type of curriculum that Wales has developed. Practitioners surveyed in Wales report feeling ready to implement the new curriculum, but there has been no systematic appraisal of the overall quality and specific competencies of Wales' teachers, and stakeholders suggest more time and targeted professional learning are needed for them to be ready.

It is also essential to consider what the new Curriculum for Wales entails in terms of equity. The Government expressed a strong commitment to equity in education and student well-being, but two main issues arise. First, there is a question of how and under what conditions the new curriculum reduces 
inequity. Without conscious monitoring and purposeful focus on equity, it is possible for flexible, child centred curriculum models to generate slightly different curricula for more and less advantaged students. Second, variations are possible in implementation from one school to the next, likely to result in a widened between-schools gap in student outcomes. In moving towards the next steps of curriculum implementation, and to prevent inequalities increasing, schools in need of support and local authorities would require special focus, on top of existing policies.

The OECD team's recommendation is to support the realisation of the curriculum across all schools in Wales. This and the actions suggested below could help continue to improve the quality of the curriculum design itself and of the support initiatives to strengthen schools' capacity to realise the curriculum.

\section{Actions to consider}

Action 2.1: Organise expert groups that can review the Curriculum for Wales building on the existing framework to ensure that it is internally coherent, well-designed and that it supports depth of understanding; and to consider assessment for learning approaches that are aligned and can gauge student progress.

- The Welsh Government should facilitate the initiative, enabling dialogue to continue between experts and practitioners, including via the Curriculum and Assessment Group, and in close coordination with Estyn and Qualifications Wales.

Action 2.2: Develop knowledge, materials and space for the local and school level to be able to understand and collectively design their own curriculum reflecting the aspirations of the framework.

- The Welsh Government should work in close collaboration with regional consortia on this building on the examples already developed by school practitioners.

Action 2.3: Invest in the development of education professionals' capacity to be the main drivers of the curriculum in schools by enhancing their skills and competencies and promoting their collaboration.

- This is a prime responsibility for the Welsh Government, NAEL, regional consortia and higher education institutions to discuss.

- The Welsh Government should guarantee the quality and consistency of professional learning across Wales, and so should NAEL for leadership development.

- The primary providers, including regional consortia and higher education institutions, should be included in the strategic discussions as well to guarantee this quality and consistency.

Action 2.4: Prioritise equity considerations in provision of professional learning, school improvement services and resourcing to avoid risks of inequalities increasing with curriculum realisation.

- The Welsh Government, in collaboration with the Strategic Education Delivery Group and regional consortia, should guarantee this prioritisation of equity by detecting underperforming schools and ensuring their support through these initiatives throughout implementation.

\section{Recommendation 3: Focusing the co-construction process on next steps for schools}

The OECD team observed a lack of clarity and of shared understanding in stakeholders' perspective on their roles. Under the new curriculum framework, teachers and school leaders are expected to become 
curriculum designers, which implies a new role for them. Responsibilities of key actors of the middle tier, including of Estyn, higher education institutions, local authorities and regional consortia, are also expected to evolve in response to the new curriculum. Having clarity on each other's roles is necessary to help stakeholders move the Welsh system from one with high-stakes accountability to one based on trust and professionalism. The Welsh Government keeps holding responsibility as a supportive leader in this regard.

Trust and collaboration will be key to make this curriculum reach its potential, but they can only work effectively if stakeholders know their roles and that of their peers, and if they trust each other to comply with their responsibilities. The Welsh Education Directorate and system leaders have a central part to play to sustain the process, helping all stakeholders build confidence and do their part to change a system while making sure their efforts are co-ordinated. The OECD team became aware that moving forward with implementation, a challenge for the Welsh Government and other system leaders would be to fine-tune and maintain unity in their messages to all relevant stakeholders, while offering some tailored communication for specific key actors, such as teachers, students, parents and school governors.

At present, Wales benefits from widespread commitment to the curriculum realisation effort. However, not all stakeholders, especially not all schools, are equally involved, ready, or confident in their ability to implement the change. At this important juncture, it will be important not to take for granted the interactions, relationships, networks and collaborations of those across the system and over time. The interdependence of those relational ties are known to ultimately influence the direction, speed, and depth of a planned change. The OECD team's recommendation is thus to focus the co-construction process on the next steps for schools, keeping the schools' perspective at the centre in order to move forward.

\section{Actions to consider}

Action 3.1: Clarify and ensure a shared understanding of each stakeholder's revised roles, responsibilities and concrete next steps in the curriculum realisation.

- Representatives in the Strategic Education Delivery Group, in collaboration with the Welsh Government, should lead this clarification task and safeguard this clarity around roles throughout implementation.

Action 3.2: Sustain the co-construction process over the medium term through system leadership and continued investment in consultation and engagement approaches that have been successful in developing shared ownership of actions and trust.

- The Welsh Government remains the leader at the service of the education system with the responsibility to support all other stakeholders through investing in co-construction and providing leadership when relevant.

Action 3.3: Continue with the clear and targeted communication strategy, which can contribute to ensuring alignment, shared purpose and dissemination of knowledge and good practices across Wales.

- The Welsh Government can guarantee communication unity and clarity across the system by continuing dialogue with other system leaders, and making sure the messages are understood and convey the same meaning to all. 


\section{Actions to consider (continued)}

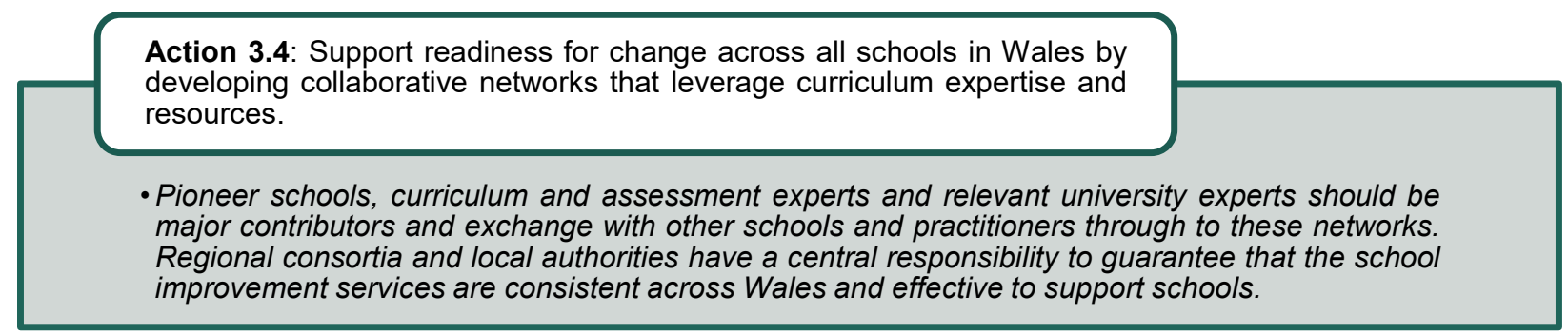

\section{Recommendation 4: Consolidating policy coherence around schools}

Shifting from what had become a managerial education system to one based on trust and professionalism still requires effort in Wales, which has consequences for curriculum implementation. Regional consortia's task to support schools is challenging as the profile and degree of involvement with the reform differs significantly from one school to the next. Evidence also suggests that a considerable proportion of schools in Wales are still not functioning as learning organisations, despite the potential of the schools as learning organisations (SLO) model to contribute to curriculum reform goals being realised. This is not an urgent issue considering most people the OECD team interviewed mentioned these policies already facilitate the realisation of the new curriculum. Realising the reform agenda will increase demand for support by schools, which may also increase the work and capacity requirements of regional consortia to respond to these demands.

The ambitious agenda in Wales has resulted in significant education reform work in a relatively short space of time across a wide range of policies and initiatives. While Wales has invested in defining a coherent education reform agenda, inevitably, there may be lack of alignment between the various policies. Policy attention should continue to focus on the four enabling objectives to successfully realise Wales' new transformational curriculum - high-quality education professionals; inspirational leaders; assessment evaluation and accountability; and excellence, equity and well-being. To reduce unnecessary complexity for teachers and schools, it will be important to have in place a process for developing and sustaining coherence across policies/initiatives over time, especially in the way they are provided to schools.

The Welsh government has also focused on transforming its assessment and evaluation approaches to fit the new curriculum. International evidence points to the necessity for some accountability framework and school-leaving qualifications to align with the new curriculum principles and approach to learning, failing which schools would leave the new curriculum aside. Without such alignment, there is a risk that teaching and learning for students aged 14 to 16 will be skewed towards the content of qualifications, and towards whichever characteristics are taken into account for school evaluations. Further communication on the development of the qualifications and the new accountability framework will be essential for the successful implementation of the new curriculum.

In addition, a prominent issue that was raised during several of the interviews with the OECD team was the need for a strategic educational research agenda. The Welsh Government and other stakeholders have recognised this issue and are drafting a national strategy for educational research. It was, however, apparent to the OECD team that there is scope for more strategic use of research to support the curriculum reform in the short-term, and overall to strengthen the quality of teaching and learning across schools in Wales. Including research can also help monitor progress in the realisation of the curriculum. The OECD team's final recommendation is to consolidate policy coherence around schools, to allow for keeping the priority focus on the curriculum while making use of and strengthening the other policy initiatives. 


\section{Actions to consider}

Action 4.1: Continue to develop the role of regional consortia by enhancing the school improvement service infrastructure, investing in professionals working in consortia across Wales, and guaranteeing alignment in implementation between the curriculum and other policies, including the Additional Learning Needs (ALN) Act.

- Regional consortia and local authorities need to continue supporting the challenge advisers, to help establish a learning culture and a focus on collaboration to bring the new curriculum to life in schools.

- Regional consortia and local authorities, with help from the Welsh Government, should also guarantee alignment in implementation between the curriculum and other policies, including the Additional Learning Needs (ALN) Act.

Action 4.2: Set learning about the new curriculum at the core of the SLO model for the coming years.

- This should be a driver of regional consortia strategy, with the two policies being systematically linked in school support initiatives. The SLO working group could provide support to ensure consistency across Wales.

Action 4.3: Continuously evaluate policy coherence across (potentially) complementary policies, especially in terms of professional standards and leadership.

- There is a specific need to clarify teacher standards, which should embed individual and collective teacher agency for school curriculum making in policy and in initial and continuing professional learning. This task is primarily for the Welsh Government to conduct, following dialogue with stakeholders, especially at local and school level.

- The second line of action is to invest in school and system leadership for curriculum design. This should be promoted by NAEL and should lead to the development, endorsement and provision of adequate training for all school and system leaders

Action 4.4: Consolidate an evaluation and assessment framework and develop a systematic and robust research agenda that align to the new curriculum.

- This is a task for the Welsh Government and the reform's Change Board in close collaboration with Qualifications Wales, Estyn and higher education institutions.

- This action implies continuing to review qualifications, the current accountability approach and its transition, as well policies for system and school external and self-evaluations to ensure they are aligned to the new curriculum's expected outcomes.

- It also requires developing a systematic and robust research agenda to monitor, evaluate and inform developments of the new curriculum

\section{A resource to help plan the next steps}

Progress has been made with the Curriculum for Wales. For the next steps, these actions require a continued concerted effort by the Welsh Government, its Education Directorate and key education stakeholders to ensure that the investments, knowledge and energy invested up to this key point result in positive change across schools in Wales. It will be important for the Welsh Government, together with key stakeholders, to reflect on the aforementioned actions and to develop a clear understanding of how to achieve them concretely, who will be responsible, and how they can be monitored. The following table is provided as a resource for reflection on how to move forward. 
Table 1. Planning the next steps for implementing the Curriculum for Wales

\begin{tabular}{|c|c|c|c|c|}
\hline Implementation levers & 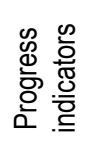 & 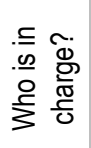 & 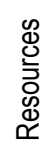 & $\stackrel{\overbrace{}}{\stackrel{\overbrace{}}{\Phi}}$ \\
\hline \multicolumn{5}{|l|}{ Developing a shared understanding of what the vision looks like in practice } \\
\hline \multicolumn{5}{|l|}{ Develop a shared overarching vision of what the curriculum implies for practice in schools } \\
\hline \multicolumn{5}{|l|}{$\begin{array}{l}\text { Define associated operational objectives and indicators to monitor progress towards achieving the } \\
\text { vision including the implementation of the curriculum }\end{array}$} \\
\hline \multicolumn{5}{|l|}{ Supporting the realisation of the curriculum across all schools in Wales } \\
\hline \multicolumn{5}{|l|}{$\begin{array}{l}\text { Organise expert groups that can review the Curriculum for Wales building on the existing framework } \\
\text { to ensure that it is internally coherent, well-designed and that it supports depth of understanding; and } \\
\text { to consider assessment for learning approaches that are aligned and can gauge student progress }\end{array}$} \\
\hline \multicolumn{5}{|l|}{$\begin{array}{l}\text { Develop knowledge, materials and space for the local and school level to be able to understand and } \\
\text { collectively design their own curriculum reflecting the aspirations of the framework }\end{array}$} \\
\hline \multicolumn{5}{|l|}{$\begin{array}{l}\text { Invest in the development of education professionals' capacity to be the main drivers of the curriculum } \\
\text { in schools by enhancing their skills and competencies and promoting their collaboration }\end{array}$} \\
\hline \multicolumn{5}{|l|}{$\begin{array}{l}\text { Prioritise equity considerations in provision of professional learning, school improvement services } \\
\text { and resourcing to avoid risks of inequalities increasing with curriculum realisation }\end{array}$} \\
\hline \multicolumn{5}{|l|}{ Focus the co-construction process on next steps for schools } \\
\hline \multicolumn{5}{|l|}{$\begin{array}{l}\text { Clarify and ensure a shared understanding of each stakeholder's revised roles, responsibilities and } \\
\text { concrete next steps in the curriculum realisation }\end{array}$} \\
\hline \multicolumn{5}{|l|}{$\begin{array}{l}\text { Sustain the co-construction process over the medium term through system leadership and continued } \\
\text { investment in consultation and engagement approaches that have been successful in developing } \\
\text { shared ownership of actions and trust }\end{array}$} \\
\hline \multicolumn{5}{|l|}{$\begin{array}{l}\text { Continue with the clear and targeted communication strategy, which can contribute to ensuring } \\
\text { alignment, shared purpose and dissemination of knowledge and good practices }\end{array}$} \\
\hline \multicolumn{5}{|l|}{$\begin{array}{l}\text { Support readiness for change across all schools in Wales by developing collaborative networks that } \\
\text { leverage curriculum expertise and resources, with participation from practitioners, Pioneer schools, } \\
\text { curriculum and assessment experts, and relevant university experts }\end{array}$} \\
\hline \multicolumn{5}{|l|}{ Consolidating policy coherence around schools } \\
\hline \multicolumn{5}{|l|}{$\begin{array}{l}\text { Continue to develop the role of regional consortia by enhancing the school improvement service } \\
\text { infrastructure, investing in professionals working in consortia across Wales, and guaranteeing } \\
\text { alignment in implementation between the curriculum and other policies, including the ALN Act }\end{array}$} \\
\hline \multicolumn{5}{|l|}{ Set learning about the new curriculum at the core of the SLO model for the coming years } \\
\hline \multicolumn{5}{|l|}{$\begin{array}{l}\text { Continuously evaluate policy coherence across (potentially) complementary policies, especially in } \\
\text { terms of professional standards and leadership }\end{array}$} \\
\hline $\begin{array}{l}\text { Consolidate an evaluation and assessment framework (including qualifications, accountability, } \\
\text { system and school evaluations) and develop a systematic and robust research agenda that align to } \\
\text { the new curriculum }\end{array}$ & & & & \\
\hline
\end{tabular}

Source: OECD (2020) Achieving the New Curriculum for Wales. 


\section{The bottom line: plan curriculum implementation from a school's perspective}

Wales (United Kingdom) is on the path to transform the way children learn, with a new curriculum aimed to prepare its children and young people to thrive at school and beyond. The new curriculum for Wales intends to create a better learning experience for students, to engage teachers' professionalism, and to contribute to the overall improvement of Welsh education. An education policy is only as good as its implementation, however, and Wales turned to the OECD for advice on the next steps to implement the curriculum. This OECD Education Policy Perspectives summarises the findings of the complete OECD report Achieving the New Curriculum for Wales. The analysis looks at the four pillars of implementation - curriculum policy design, stakeholders' engagement, policy context and implementation strategy - and builds upon the literature and experiences of OECD countries to provide tailored advice to Wales on the actions it could take to ready the system for further development and implementation. This document holds value not only for Wales, but also for other education systems across the OECD looking to implement a curriculum or to enhance their implementation processes altogether.

\section{Implementing policies: supporting change in education}

This document was prepared by the Implementing Education Policies (IEP) team at the OECD.

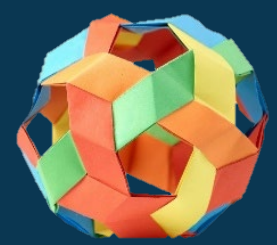

The OECD programme Implementing Policies: Supporting Effective Change in Education offers peer learning and tailored support for countries and jurisdictions to help them achieve success in the implementation of their policies and reforms in school education. The tailored support consists of three complementary strands of work that target countries' and jurisdictions' needs: policy and implementation assessment, strategic advice and implementation seminars.

\section{For more information:}

Contact: Beatriz Pont, project leader, Beatriz.Pont@oecd.org

Website: OECD Implementing Education Policies

OECD (2020) Achieving the New Curriculum for Wales, Implementing Education Policies, OECD Publishing, Paris 


\section{References}

OECD (2020), Achieving the New Curriculum for Wales, Implementing Education Policies, OECD

Publishing, Paris, https://dx.doi.org/10.1787/4b483953-en.

OECD (2018), Developing Schools as Learning Organisations in Wales, Implementing Education

Policies, OECD Publishing, Paris, https://dx.doi.org/10.1787/9789264307193-en.

OECD (2017), The Welsh Education Reform Journey: A rapid policy assessment, OECD Publishing,

Paris, http://www.oecd.org/education/The-Welsh-Education-Reform-Journey.pdf (accessed on

3 January 2020).

OECD (2014), Improving Schools in Wales: An OECD Perspective, OECD Publishing,

http://www.oecd.org/education/Improving-schools-in-Wales.pdf.

Viennet, R. and B. Pont (2017), "Education policy implementation: A literature review and proposed framework", OECD Education Working Papers, No. 162, OECD Publishing, Paris, https://dx.doi.org/10.1787/fc467a64-en.

Welsh Government (2020), Curriculum for Wales guidance, Welsh Government, Cardiff, https://hwb.gov.wales/storage/b44ad45b-ff78-430a-9423-36feb86aaf7e/curriculum-for-walesguidance.pdf.

Welsh Government (2017), Education in Wales: Our national mission - Action plan 2017-21, https://gov.wales/sites/default/files/publications/2018-03/education-in-wales-our-national-mission.pdf (accessed on 3 January 2020).

This work is published under the responsibility of the Secretary-General of the OECD. The opinions expressed and arguments employed herein do not necessarily reflect the official views of OECD member countries.

This document, as well as any data and any map included herein, are without prejudice to the status of or sovereignty over any territory, to the delimitation of international frontiers and boundaries and to the name of any territory, city or area.

The statistical data for Israel are supplied by and are under the responsibility of the relevant Israeli authorities. The use of such data by the OECD is without prejudice to the status of the Golan Heights, East Jerusalem and Israeli settlements in the West Bank under the terms of international law.

You can copy, download or print OECD content for your own use, and you can include excerpts from OECD publications, databases and multimedia products in your own documents, presentations, blogs, websites and teaching materials, provided that suitable acknowledgment of OECD as source and copyright owner is given. All requests for commercial use and translation rights should be submitted to rights@oecd.org. 